\title{
Strategies of Cell Signaling and Critical Focus on Etiology of Hepatocellular Carcinoma
}

\author{
Mohammad Habeeb 1,2 (D), Abimanyu Sugumaran 2,* (D) \\ 1 Crescent School of Pharmacy, B.S. Abdur Rahman Crescent Institute of Science and Technology, Chennai-600048, India; \\ mdhabeebqa@gmail.com (M.H.); \\ 2 Department of Pharmaceutics, SRM College of Pharmacy, SRM Institute of Science and Technology, Kattankulathur- \\ 603203, India; abipharmastar@gmail.com (A.S.); \\ * Correspondence: abipharmastar@gmail.com (A.S.);
}

Scopus Author ID 37666229600

Received: 18.07.2021; Revised: 1.09.2021; Accepted: 5.09.2021; Published: 17.10.2021

\begin{abstract}
Hepatocellular carcinoma is an atypical biological cell process that is frequently identified at an advanced stage, with no promising therapeutic options available. Hepatocarcinogenesis is connected to a range of cellular signaling pathways, notably Wnt- $\beta$-catenin (canonical Wnt pathway), nuclear factor-B, and YAP-HIPPO (Yes-associated protein Salvador-Warts-Hippo pathway); each of these is considered a potential pharmacological candidate. Inflammation in the liver for a long time and damage play a big role in the incidence and development of HCC. HCC incidence rates go up by the many variables such as sex, age, ethnicity, and demographics are all factors to consider, and the leading causes of infection by the chronic or hepatitis B virus (HBV), hepatitis C virus (HCV), nutrient pollutants, ecological poisons, tobacco smoldering, and genetic disorders, which are all carcinogens. In this review, we expanded on our existing empathetic of the signaling pathways involved in the development and genesis of HCC. We also encapsulated the etiology of HCC, with a focus on HCC triggered by nonalcoholic fatty liver disease (NAFLD) and alcoholic fatty liver disease (AFLD). In this review, we forecasted potential therapeutic drug targets.
\end{abstract}

Keywords: hepatocellular carcinoma; cell signaling; alcoholic fatty liver diseases; anticancer drugs.

(C) 2021 by the authors. This article is an open-access article distributed under the terms and conditions of the Creative Commons Attribution (CC BY) license (https://creativecommons.org/licenses/by/4.0/).

\section{Introduction}

Cancer is a worldwide leading public health problem and the second leading cause of death in the world. The coronavirus disease 2019 (COVID19) pandemic hampered cancer diagnosis and treatment in 2020 [1]. The International Agency for Cancer Research (IARC), published its latest global cancer burden estimates on 15 December 2020. The Database of GLOBOCAN 2020, which is offered online through the IARC Global Cancer Observatory (https://gco.iarc.fr/>), allows evaluation of in 185 countries the incidence of cancer and death for 36 different cancers and then all cancer locations blended for the year 2020 [2]. In 2020, the world melanoma load was expected to increase to 10.0 million deaths and 19.3 million new cases. The main liver malignancy is the sixth furthermost frequently analyzed melanoma and the third foremost reason for cancer demise worldwide in 2020, with roughly 906,000 new incidents and 830,000 demises. Men have 2 to 3 times greater rates of both cases and mortality than women. Then among women in most regions, Liver malignancy is the most recurrent cause of death in men. HBV infection is the most prominent risk factor for the development of HCC, accounting for $50 \%$ of cases. [3].

The threat posed by hepatitis $\mathrm{C}$ virus $(\mathrm{HCV})$ infection has considerably diminished due to individuals achieving sustained virologic response (SVR) with antiviral medications. 
Nonetheless, even after HCV eradication, individuals with cirrhosis are thought to be at an increased risk of developing HCC. Non-alcoholic steatohepatitis (NASH), which is frequently linked with metabolic syndrome or type 2 diabetes, is fetching the wildest growing etiology of HCC [4]. Signaling targets Related and Molecular pathways with HCC expansion and quite a lot of pathways of cellular signaling targets drawn in hepatocarcinogenesis such as Yesassociated Protein-Hippo Pathway (YAP-HIPPO), NF- $\kappa \mathrm{B}$ and $\mathrm{Wnt} / \mathrm{B}$-catenin have been premeditated. Furthermore, the lipid metabolism functioned by PPARc, the involvement of changes in epigenetic including histone methylation, non-coding RNAs, acetylation, and DNA methylation have long been promoted as imperative progressions in the advancement of liver melanoma. The following sections will discuss the specific features of every pathway of cellular targets and their part in liver malignancy [5].

\section{Molecular Pathways Associated with HCC}

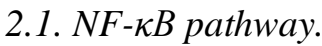

Genetic alterations, long-lasting inflammation, tissue transformation, and alters in the signaling of cells are assumed to be vital methods in the advance and evolution of liver tumors [6]. The factors of NF- $\mathrm{KB}$ transcription regulated the involvement of genes in inflammatory and immune responses was reported in (Figure 1). The subsequent cytokines proinflammatory and long-lasting inflammation are triggered due to alteration in signaling pathways, leading to a possibly very harmful to the hepatocytes mentioned in Table 1.

To know the role of NF- $\mathrm{KB}$ in the evolution of liver disorders, numerous investigations have been done, but it is also connected to fibrosis, inflammation triggering, liver damage, and the factors of NF- $\mathrm{kB}$ signaling [7]. Expansion liver cancer is associated with tumor progression, cancer initiation, apoptosis inhibition, and tumor cell proliferation.

\subsection{WNT/ß-catenin signaling.}

The overactivation of the $B$-catenin signaling pathway allows the proliferation of specific genes such as cyclin D1 and c-Myc, which leads to HCC [8]. The suppression of the tumor defeats adenomatous polyposis coli (APC), which causes unswerving mutation due to stimulation of Oncogenes, which hinders the protein from being degraded by the proteasome. Additionally, Gene mutation such as APOB, MLL2, ARID2, TERT, and NFE2L2 and instigation of the (HGFR or c-MET) hepatocyte growth factor receptor leads to the tumorigenesis these factors are influenced by the oncogenic instigation of $\beta$-Catenin [9].

\subsection{Yes-associated Protein-(YAP-) Hippo.}

A protein type of YAP1 that performance apoptotic genes irresistible and also the transcriptional control of genes tangled in the propagation of HCC cells.[10]. Oncogene has numerous YAP1 that cause human melanoma. When the yes-linked protein 1 (YAP1) and their transcriptional paralog coactivator accompanied by PDZ-binding motif (TAZ) are sequester in the cytoplasm with the support of 14-3-3 proteins and also phosphorylated on a serine 314 residue they are represented in (Figure 1). When the Hippo pathway is deactivated, YAP1/TAZ enters the nucleus and controls gene expression [11]. The hepatoma proliferation of cells, invasion, metastasis, and apoptosis, and the apparent changes in the size of the liver cells are due to the action of the Hippo-YAP cellular mechanism. Overexpression of YAP causes an increased mass of the liver tissue by 2 -folds in the liver of transgenic mice when the birth after 
the first week. They also observed greatly decreased liver tumors. On the other hand, parenchymal cells of the liver stabilized steadily due to the restoration of YAP expression [12].

\subsection{PPARc activation.}

A transcription nuclear factor (PPARc) when its stimulation was built up causes the action of the anti-inflammatory, lipid metabolism, and peripheral cells sensitization [13]. PPARx activated agonists to Thiazolidinedione have remained revealed in both in vivo and invitro and shown an antitumoral effect in numerous types of carcinomas. It also revealed the decrease in the proliferation of cells and preventing the variations in carcinoma cells. PPARc ligands, such as SR1664, are small molecules that bind to the PPARc receptor, demonstrated efficacy in reducing type 1 collagen quantity and preventing HSC stimulation in a model animal of liver damage, as well as the capability to protect from HCC development [14].

\subsection{DNA methylation.}

The variations related to cell proliferation, adhesion, invasion, motility, and cell signaling by this modification's genes are more injured their mechanisms were represented in (Table-I). Methylation of $\mathrm{CpG}$ promotors is a typical DNA amendment and is controlled through (DNMTs) methyltransferases of DNA represented in (Figure 1). The DNMT1 enzyme contributes to the formation and maintenance of specific tissue and patterns of cytosine methylation [15]. Oh, et al. was the first one to identify the DNMT1 in humans. He found the overexpression of DNMT1 in the tissue of human hepato-carcinoma and advancement of gene methylation, such as e-cadherin, cancer hyper-Methylate's 1 (HIC-1), P16, P15, and domain 1 isoform A of the family of Ras associations (RASSF1A) were reported to be accompanying with a poor prognosis[16].

\subsection{MicroRNAs (miRNAs)}

In terms of cancer development, miRNA dysregulation leads to anomalous expression of metastasis, which promotes progression, invasion, and target genes. MiRNAs such as miR122 and miR-221 have been connected to the advance of HCC [17]. MiR-122 is downregulated during the early stages of experimentally persuaded hepatocarcinogenesis; little echelons of miR-122 in HCC patients are associated with metastasis and a poor prognosis. In miR-122 knockout mice, there was an increase in liver inflammation, fibrosis, steatohepatitis, and HCC [18]. Hepatocarcinogenesis is linked to genomic changes that are influenced by genetic and epigenetic changes. HCC progress is alienated into initial and later stages; importantly, epigenetic parameters are regulation is engaged in both stages of $\mathrm{HCC}$ advance. The following segment discusses the foremost epigenetic changes associated with the advancement of HCC19].

\subsection{Histone modifications in HCC.}

Enzymes that augment and eradicate groups of acetyls from histones control these processes. Histone deacetylation is linked to HCC pathogenesis in a specific way through the action of histone deacetylase 3 , which is a crucial component. Regulating in vitro cell propagation of HepG2 model, histone deacetylase 6 as well, which restricts tumors concluded autophagic cell death [20]. Histone modifications and transcriptional factors requisite with target gene supporters due to modifications in the (H3K9) histone 3 lysine 9 acetylation. The 
Human (HepG2) HCC cells in culture have a lower nucleosome density than normal cells and $\mathrm{H} 3 \mathrm{~K} 9$ acetylation, indicating that acetylation of $\mathrm{H} 3 \mathrm{~K} 9$ can occur a significant role in nucleosome relaxation and tumorigenesis activation [21].

A further research established the relevance of $\mathrm{H} 3 \mathrm{~K} 9$ acetylation by $\mathrm{CBP} / \mathrm{p} 300$ analysis, which acts as a histone acetyltransferase (HAT) and is involved in a variety of biological processes. The findings recommend that decreasing CBP/p300 diminishes $\mathrm{H} 3 \mathrm{~K} 9$ acetylation, which plays a vital part in HCC malignant transformation, proliferation, apoptosis, and invasion [22-24].

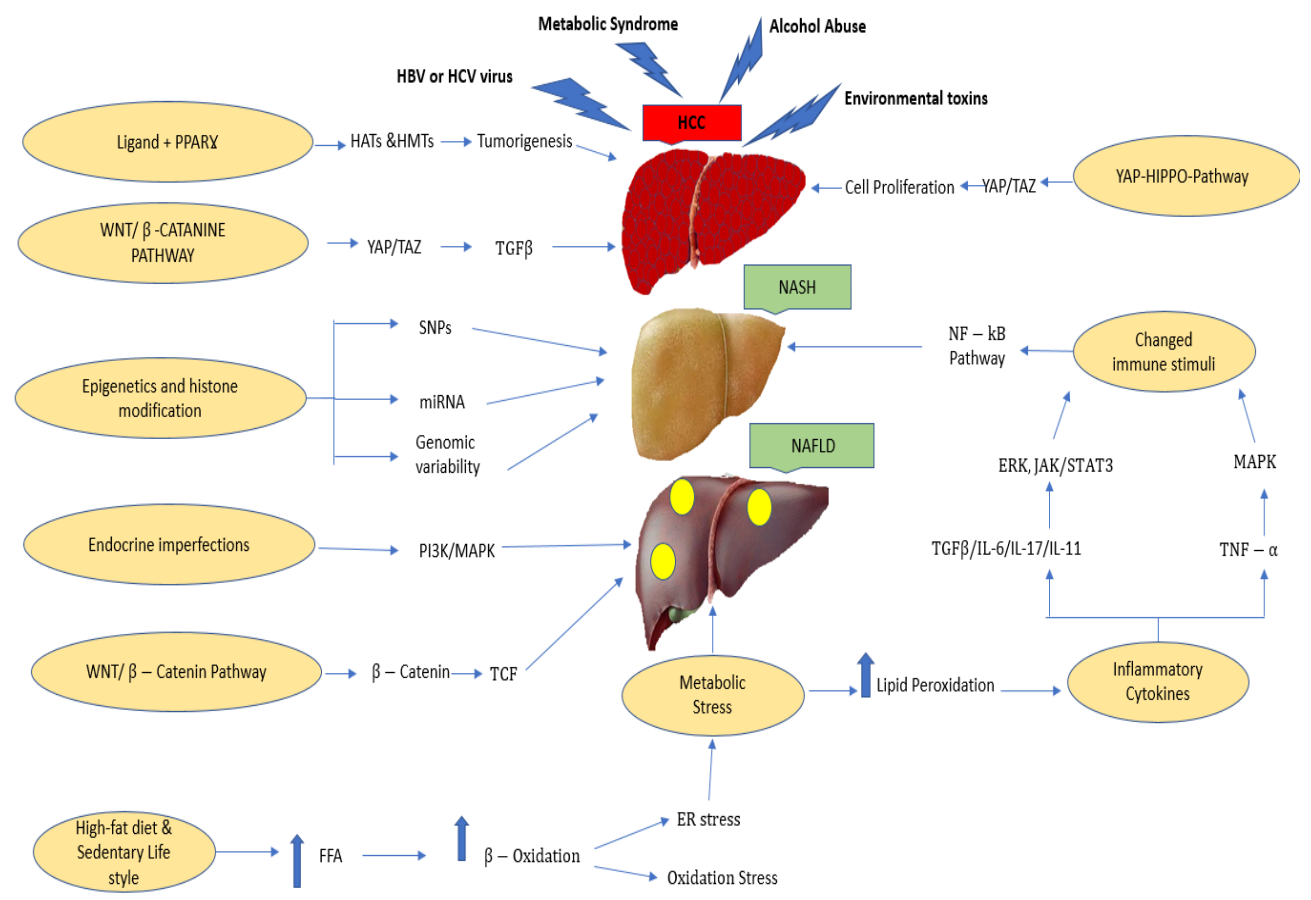

Figure 1. Core mechanisms intricate in the growth of hepato-carcinoma.

The enduring contact of hepatoxic materials grounds the instigation of the signaling paths such as YAZ-HIPPO receptors regulate Pathway, WNT/AXIN Pathway, NF- $\kappa$ B signaling pathway, which causes the tumor formation and metastasis and also resistance to antimalignancy drugs. PPARc destined to its ligands has a twofold effect, obstructing the different cellular signaling pathways such as of NF- $\mathrm{KB}$ and $\beta$-catenin; nevertheless, binding to the PPRE section can upsurge the activation of genes intricate in, obstructing of cell proliferation, and metastasis and cell apoptosis.

Various stress metabolic pathways of signaling (IL-6, IL-17, IL-11, and TGF-3) cytokine production (hedgehog and NF- $\mathrm{kB}$ ) Pro-fibrogenic mediators, FFAs ER-stress, altered immune response, which causes of advancement of $\mathrm{HCC}$ in accompanying with NASH/NAFLD. FFAs ER-stress, cytokine production (IL-6, IL-17, IL-11, and TGF-ß), improved immune response, Pro-fibrogenic mediators (hedgehog and NF- $\kappa \mathrm{B}$ ) the expansion of NAFLD/NASH related HCC. Non-alcoholic fatty liver disease (NAFLD); hepatocellular carcinoma (HCC); non-alcoholic steatohepatitis (NASH); mitogen-activated protein kinase (MAPK); tumour necrosis factor-alpha (TNF- $\alpha$ ); transforming growth factor $\beta($ TGF- $\beta$ ); free fatty acids (FFAs); nuclear factor kappa-light-chain-enhancer of activated (NFkB); interleukin6 (IL-6); extracellular receptor kinase(ERK); single nucleotide polymorphisms(SNPs); endoplasmic reticulum(ER); non-alcoholic steatohepatitis(NASH); signal transducer and activator of transcription (STAT); phosphatidylinositol 3-kinases(PI3K); interleukin-11(IL11); micro RNA (miRNA); Janus kinase(JAK); interleukin-17(IL-17). 
Table 1. List of potential therapeutic drugs and molecular pathways for HCC.

\begin{tabular}{|c|c|c|c|c|c|}
\hline S. no & $\begin{array}{l}\text { Molecular } \\
\text { Targets }\end{array}$ & Drug & Mechanisms & Phase & Reference \\
\hline 1 & $\begin{array}{l}\text { PDGFR, } \\
\text { VEGFR }\end{array}$ & Linifanib & $\begin{array}{l}\text { Inhibition of tumor evolution of liver of mouse xenografts by the } \\
\text { receptor tyrosine kinase-inhibitor illustrates the overall survival } \\
\text { of patients with unconventional liver melanoma as equated to } \\
\text { sorafenib. }\end{array}$ & III & {$[25,26]$} \\
\hline 2 & $\begin{array}{l}\text { c-Kit, Flt-3, } \\
\text { PDGFP, } \\
\text { VEGF }\end{array}$ & Sunitinib & $\begin{array}{l}\text { It targets the cellular signaling at the various (RTKs) receptor } \\
\text { tyrosine kinases. It displays a very low survival rate than the } \\
\text { sorafenib. But in Xenografts of HCC, it shows enhanced } \\
\text { apoptosis. }\end{array}$ & III & [27] \\
\hline 3 & $\begin{array}{l}\text { FGFR, } \\
\text { PDGFR, } \\
\text { VEGFR }\end{array}$ & $\begin{array}{l}\text { TSU-68 } \\
\text { (Orantinib) }\end{array}$ & $\begin{array}{l}\text { Tyrosine-kinase inhibitor Overwhelms the tumor progress of } \\
\text { hypodermically co-injected in (Huh7/WI-38) liver carcinoma } \\
\text { cell lines. Orntinib collectively with TACE confirms no progress } \\
\text { in HCC by acts on the VEGFR. }\end{array}$ & III & [28] \\
\hline 4 & $\begin{array}{l}\text { FGFR, } \\
\text { VEGFR }\end{array}$ & Brivanib & $\begin{array}{l}\text { Tyrosine-kinase inhibitor It acts by enhancing the apoptosis and } \\
\text { decreasing the micro-vessel load, and hampered the VEGFR } \\
\text { phosphorylation. }\end{array}$ & III & [29] \\
\hline 5 & VEGFR & Cediranib & $\begin{array}{l}\text { Tyrosine kinase inhibitor shows high toxicity and is ineffective } \\
\text { for patients with unresectable or metastatic HCC }\end{array}$ & II & {$[30,31]$} \\
\hline 6 & EGFR & Cetuximab & $\begin{array}{l}\text { It displays a more retort in advanced stages of liver carcinoma } \\
\text { observed in the chimeric mouse. }\end{array}$ & II & [32] \\
\hline 7 & VEGF & Bevacizumab & $\begin{array}{l}\text { Monoclonal antibody Hinders tumor advancement of HCC cell } \\
\text { line and xenografts of patient-derived HCC. }\end{array}$ & II & [33] \\
\hline 8 & $\begin{array}{l}\text { c-KIT, Flt- } \\
\text { 3, FGFR, } \\
\text { VEGFR }\end{array}$ & Dovitinib & $\begin{array}{l}\text { Dovitinib works through RTKs and the platelet-derived growth } \\
\text { factor receptor. In another study, it was discovered that } \\
\text { metastasis occurs in the xenograft model. }\end{array}$ & II & [34] \\
\hline 9 & EGFR & Erlotinib & $\begin{array}{l}\text { Tyrosine kinase inhibitor Displays a sustained progression-free } \\
\text { survival and complete survival in patients with unresectable } \\
\text { HCC. }\end{array}$ & II & [35] \\
\hline 10 & EGFR & Gefitinib & $\begin{array}{l}\text { It acts by inhibiting the mechanism of TGF- } \alpha \text { /EGFR pathway, } \\
\text { which is the influence for the growth of HCC. }\end{array}$ & II & [36] \\
\hline 11 & MEK1 & Selumetinib & $\begin{array}{l}\text { Tyrosine kinase inhibitor defeats the tumor progress of HCC } \\
\text { xenograft mouse model. It also acts by (MEK) mitogen-activated } \\
\text { protein kinase and the (ERK) extracellular pathway. }\end{array}$ & II & [37] \\
\hline 12 & $\begin{array}{l}\text { VEGFR, } \\
\text { PDGFR, } \\
\text { FGFR- } \\
\text { 1Raf, RET, } \\
\text { c-KIT } \\
\text { IGF/IGFR }\end{array}$ & $\begin{array}{l}\text { BAY73-4506 } \\
\text { BIIB922 }\end{array}$ & Tyrosine kinase inhibitor acts on the advanced stages of HCC. & I & {$[38,39]$} \\
\hline 13 & IGF/IGFR & AVE1642 & $\begin{array}{l}\text { A stimulated IGF/IGF-1R pathways signaling is connected with } \\
\text { activation of the Ras- MAPK pathways and PI 3-Kinase } \\
\text { pathway. These paths trigger impulsive bio-events, such as cell } \\
\text { growth, cellular proliferation, cell survival, and protein synthesis. } \\
\text { A greater level of IGF-2 is observed in patients with HCC. }\end{array}$ & I & [40] \\
\hline
\end{tabular}

\section{Causes of HCC by Virus and Additional Sources}

HCC is a traditional independent predictor in (HBV) Chronic hepatitis B virus and is also connected with (HCV) hepatitis $\mathrm{C}$ virus. These types of contaminations may contribute to a percentage around 75-80 which is connected with HCC and blight of globally over 240 million persons [41]. The cause of p53 hindered oxidative stress or swelling, which creates hepatocarcinogenesis due to the addition of genetic information of this (HBV) virus into the genome of humans. HBV-persuaded HCC includes a range of systems such as propagation along with the failure of cell growth (triggered by p53 hindered), prolonged cycles of necrosis and rejuvenation (as a result of inflammation), and stimulation of numerous mechanisms of oncogenic factors such as the PI3K/Akt/STAT3 route and (induction of oxidative pressure) $\mathrm{Wnt} / \mathrm{b}$-catenin, all of which prime to genomic instability was leads to be mutually non-cirrhotic and cirrhotic reported in (Figure 2) [42]. In contrast to $\mathrm{HBV}$, the (HCV) virus of Hepatitis C is a nonintegrating virus consisting of single-stranded RNA that is part of the Flaviviridae family's genus Hepacivirus. HCV-induced hepatocarcinogenesis is an extremely complex 
process that begins with the creation of $\mathrm{HCV}$ infection and progresses to chronic inflammatory processes, which leads to the production of HCC and liver cirrhosis [43].

\subsection{Carcinogens and HCC.}

Chemical carcinogens, in moreover to viruses of hepatitis, plays a key part in the primes to HCC. Carcinogens such as vinyl chloride, aflatoxins, arsenic, tobacco smoke, and other chemicals reason for DNA impairment, persuade liver cirrhosis, and process to HCC, either self-sufficiently or in blend with viruses was reported in (Figure 2). Aflatoxin is an effective carcinogen of the liver formed by the fungus called Aspergillus, which has been initiated to foul foods, namely peanuts, corn, and soya beans, that have been stowed in soggy circumstances. Some of the mycotoxins may cause a mutation in the suppressor genes of p53 in the tumor, resulting in an uncontrolled advance of liver cells and the growth of HCC. (nitrosamines) areca nut, (polycyclic aromatic hydrocarbons and 4-aminobiphenyl and) Tobacco smoke, and (safrole) shrubberies of betel have been a trigger to hepatotoxicity [4446].

\subsection{Inherited diseases and HCC.}

a1-antitrypsin deficiency, hemochromatosis caused by the Hereditary, diseases like Wilson's, and hepatic porphyria are accompanying Complex peril of HCC development. These hereditary illnesses are designed to enhance hepatocarcinogenesis as a moment of the augmented inflammatory process and hepatocellular damage [47].

\subsection{Metabolic syndrome and HCC.}

Metabolic syndrome, a constituent of Diabetes mellitus, has been linked to $7 \%$ approximately of all HCC incidents worldwide. Diabetes is complexed with HCC independently caused by the hepatitis virus, with diabetic patients having a 2-3-fold increased risk of emerging HCC compared to non-diabetic controls. Diabetes has a strong association with the pathogenesis of HCC due to physiological circumstances such as hyperglycemia, hyperinsulinemia, insulin sensitivity, and insulin-like growth factor signaling stimulation pathways [48].

Obesity, a compulsive state categorized due to insulin confrontation, inflammation, and hyperinsulinemia, is closely linked to HCC. Dysregulated adipokines are increasing the reactive oxygen species, which leads to restoration of adipose tissue. The in-modification of the gut microbiota and dysregulated microRNA enhance the comparative risk of HCC in obese individuals. As a result, Obesity is among the most important likely reasons for NAFLD, which seems to be a risk factor for HCC [49].

\subsection{Fatty liver disease related to HCC.}

In the last 10 years, the fatty liver ailment has emerged as one of the leading causes of chronic liver illness that progresses to HCC.

\subsubsection{Non-alcoholic Fatty Liver Disease (NAFLD)-Associated HCC.}

The accumulation of excessive lipids in the liver (steatosis) is an indication of NAFLD. After a long period of stabilizing in steatosis, which leads to steatohepatitis, an increase in 
lipids causes inflammation to injure the liver. It is the main cause of liver cirrhosis and then HCC. Obesity, high blood pressure, dyslipidemia, resistance to insulin, and diabetes of type 2 are all commonly interlinked with NAFLD. It has been proven to increase the incidence of HCC by 1.5-4 times, either by promoting the growth of NAFLD or by recklessly exerting a carcinogenic effect. (Figure 2) indicated that hepatic iron overflowing force is associated with the development of $\mathrm{HCC}$ in NASH patients. [50]. The mechanism underlying the progression of NAFLD-associated HCC is complex. In the nonexistence of excessive alcohol consumption, hepatic lipid aggregation due to intake of calories of high (Like more carbohydrate and excessive dietary fat) and reduced physical work to the body is a significant factor in the development of NAFLD [51].

\subsubsection{HCC in related to (AFLD)- Alcoholic Fatty Liver.}

AFLD is mainly due to the extreme intake of alcohol, which leads to injury of liver cells through the fat buildup, scarring, and inflammation eventually is the major source of HCC, which can be fatal.

Worldwide, the AFLD predominance is rising, and it has become a momentous indication of liver disorders' burden, taking account of HCC connected deaths was around $30 \%$. Extreme alcohol ingesting ( $>14$ drinks per week for men and $>7$ drinks per week for women) is thought to source AFLD [52]. Females have inferior gastric alcohol dehydrogenase (ADH) action, and estrogen levels were triggered by Kupffer cells due to higher gut penetrability and the enhancing the concentrations of endotoxins in the portal, resulting in liver damage due to induced alcohol was reported in (Figure 2).

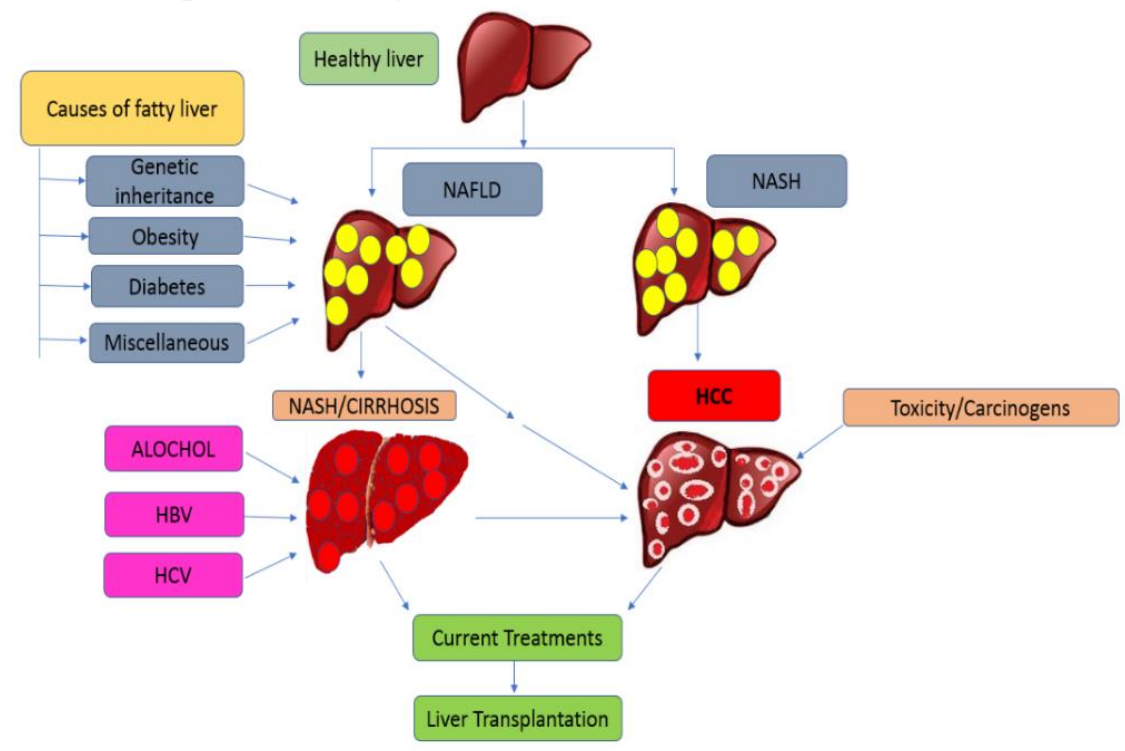

Figure 2. The molecular mechanisms behind non-alcoholic and alcoholic-related HCC are distinct. The primary causes of NAFLD and AFLD are a high-calorie diet and excessive alcohol consumption. Despite their different pathogenic origins, the clinical spectrum of liver damage in promoting migration and development in NAFLD and AFLD has similar molecular pathways.

Furthermore, investigations have exposed that American drinkers have folds of two spikes in liver enzymes when contrasted to Whites, Blacks, and Hispanics. Because there is no notable change between further ethnic groups, aspects such as polymorphism of genes connected with the metabolism of alcohol (ADH, CYP2E1) and enzymes of antioxidant, as well as genes that are responsible for coding of cytokines, are being studied about the alcoholic liver disease [53]. 
First-Line Therapies with Sorafenib is a tyrosine kinase receptor (TKR) inhibitor. Sorafenib is considered to be an approved drug for the treatment of systemic in advanced HCC patients with no contenders in the surgical resection or transplantation of the life mentioned in (Table 1). Sorafenib was evaluated in phase III clinical standardized controlled trial (SHARP); it improved survival by 10.7 months compared to 7.9 months compared to placebo; adverse events included tiredness, diarrhea, and hand-foot skin response. [54-56].

Investigators' findings have shown that the sorafenib action is interrelated to its capability to accurately alter erythroblastosis (Ets-1) protein of glycosylation in the cells of HCC, dramatically the survival rate was enhanced in the patients of HCC was advanced represented in (Table I) [57]. Additionally, the drug called Lenvatinib is considered a first-line medicine that may improve survival in the patients $\mathrm{HCC}$ is an advanced condition and cannot remove the tumor through surgically it acts by inhibiting angiogenesis and lymphangiogenesis. [58].

It was observed during the studies of Phase I studies recommended the drug lenvatinib. These studies advised that lenvatinib is considered effective in patients where the tumor of the liver is in an advanced stage with advanced HCC and a result mentioned as concentrations of $12 \mathrm{mg}$ and $8 \mathrm{mg}$ of Child-Pugh A or B score respectively. The most common side effects of oral lenvatinib at a dose of $12 \mathrm{mg}$ daily were hypertension, diarrhea, reduced hungriness, and weight loss. Second-Line therapies include Regorafenib is a drug advanced Bayer's second-line oral medicine for unresectable HCC was FDA in June 2017 [59]. Pirfenidone has recently been discovered to bind to the ligand active affinity province of PPAR $\alpha$, which corresponds to PPARc homolog, galvanizing the SIRT1/LкB1/pAMPK signifying their capability to amend the epigenetic marks of the H3K9. A new drug investigated from the human monoclonal antibody of anti-VEGFR2 blocks the binding of ligand to VEGFR. [60-61].

\section{Conclusions and Future Direction}

HCC has a complicated etiology, with numerous important signaling pathways implicated in its progression. Conversely, because the use of combination treatment may pose concerns such as usability and drug-drug interactions, it may be preferable to use an alternative, multi-targeting molecular medicines that affect numerous signaling pathways and have distinct mechanisms of action. Although HCC is a complicated disease that causes dysregulation of several molecular pathways, finding regulatory proteins that can block two or more main signaling pathways at the same time would be a wonderful strategy. Multimodal studies including two or three medications that affect the complicated network of signaling pathways may be required to regulate tumor growth and survival eventually.

Conversely, the use of combination therapy may raise concerns such as tolerability and drug-drug interactions, necessitating the use of alternative, molecularly targeted medicines. By selectively delivering therapeutic medications into tumor areas, targeted drug delivery systems (DDS) have shown significant promise in treating HCC. DDS has the potential to overcome the constraints treatments. Despite several preclinical investigations, no targeted DDS for HCC has yet to be developed for clinical use. HCC caused by NAFLD and AFLD is a serious public health problem that can be avoided. In the case of NAFLD, dietary changes and increased physical activity and alcohol abstain in the case of AFLD are the most extensively used therapeutic approaches. Additional tailored treatment options may improve healthcare and patient care quality, lowering mortality rates. In patients who do not respond to lifestyle improvements, other options include pharmaceutical treatment and bariatric surgery, are 
explored. In conclusion, it is important to improve diagnostic methods for liver melanoma early detection. Significant advancements in exploring all potential liver cancer targets, including genetic, immunological, and molecular methods, must be established. If we use a translational strategy, researchers may discover effective therapies to combat HCC.

\section{Funding}

This research received no external funding.

\section{Acknowledgments}

This review has no acknowledgment.

\section{Conflicts of Interest}

The authors declare no conflict of interest.

\section{References}

1. Valencia, D.N. Brief Review on COVID-19: The 2020 Pandemic Caused by SARS-CoV-2. Cureus 2020, 12, http://doi.org/10.7759/cureus.7386.

2. Ferlay, J.; Colombet, M.; Soerjomataram, I.; Mathers, C.; Parkin, D.M.; Piñeros, M.; Znaor, A.; Bray, F. Estimating the global cancer incidence and mortality in 2018: GLOBOCAN sources and methods. Int. J. Cancer 2019, 144, 1941-1953, http://doi.org/10.1002/ijc.31937.

3. Sung, H.; Ferlay, J.; Siegel, R.L.; Laversanne, M.; Soerjomataram, I.; Jemal, A.; Bray, F. Global cancer statistics 2020: GLOBOCAN estimates of incidence and mortality worldwide for 36 cancers in 185 countries. CA. Cancer J. Clin. 2021, http://doi.org/10.3322/caac.21660.

4. Llovet, J.M.; Kelley, R.K.; Villanueva, A.; Singal, A.G.; Pikarsky, E.; Roayaie, S.; Lencioni, R.; Koike, K.; Zucman-Rossi, J.; Finn, R.S. Hepatocellular carcinoma. Nat. Rev. Dis. Prim. 2021, 7, 1-28, http://doi.org/10.1038/s41572-020-00240-3

5. Kanwal, F.; Kramer, J.; Asch, S.M.; Chayanupatkul, M.; Cao, Y.; El-Serag, H.B. Risk of Hepatocellular Cancer in HCV Patients Treated With Direct-Acting Antiviral Agents. Gastroenterology 2017, 153, 9961005.e1, http://doi.org/10.1053/j.gastro.2017.06.012.

6. Fitzmaurice, C.; Akinyemiju, T.; Abera, S.; Ahmed, M.; Alam, N.; Alemayohu, M.A.; Allen, C.; Al-Raddadi, R.; Alvis-Guzman, N.; Amoako, Y. The burden of primary liver cancer and underlying etiologies from 1990 to 2015 at the global, regional, and national level results from the global burden of disease study 2015. JAMA Oncol. 2017, 3, 1683-1691, http://doi.org/10.1001/jamaoncol.2017.3055.

7. Estes, C.; Razavi, H.; Loomba, R.; Younossi, Z.; Sanyal, A.J. Modeling the epidemic of non-alcoholic fatty liver disease demonstrates an exponential increase in burden of disease. Hepatology 2018, 67, 123-133, http://doi.org/10.1002/hep.29466.

8. Li, J.; Li, M.; Wang, T.; Liu, X.; Zhu, X.; Dai, Y.; Zhai, K.; Liu, Y.; Lin, J.; Ge, R. SLC38A4 functions as a tumour suppressor in hepatocellular carcinoma through modulating Wnt/ $\beta$-catenin/MYC/HMGCS2 axis. $B r$. J. Cancer 2021, 1-12, http://doi.org/10.1038/s41416-021-01490-y.

9. Jindal, A.; Thadi, A.; Shailubhai, K. Hepatocellular Carcinoma: Etiology and Current and Future Drugs. J. Clin. Exp. Hepatol. 2019, 9, 221-232, http://doi.org/10.1016/j.jceh.2019.01.004.

10. Gong, N.; Ma, X.; Ye, X.; Zhou, Q.; Chen, X.; Tan, X.; Yao, S.; Huo, S.; Zhang, T.; Chen, S. Carbon-dotsupported atomically dispersed gold as a mitochondrial oxidative stress amplifier for cancer treatment. Nat. Nanotechnolology 2019, 14, 379-387, http://doi.org/10.1038/s41565-019-0373-6.

11. Czauderna, C.; Castven, D.; Mahn, F.L.; Marquardt, J.U. Context-dependent role of NF-אB signaling in primary liver cancer-from tumor development to therapeutic implications. Cancers (Basel) 2019, 11, 1053, http://doi.org/10.3390/cancers11081053.

12. Li, G.; Liu, D.; Kimchi, E.T.; Kaifi, J.T.; Qi, X.; Manjunath, Y.; Liu, X.; Deering, T.; Avella, D.M.; Fox, T. Nanoliposome C6-Ceramide Increases the Anti-tumor Immune Response and Slows Growth of Liver Tumors in Mice. Gastroenterology 2018, 154, 1024-1036.e9, http://doi.org/10.1053/j.gastro.2017.10.050. 
13. Ueshima, E.; Nishiofuku, H.; Takaki, H.; Hirata, Y.; Kodama, H.; Tanaka, T.; Kichikawa, K.; Yamakado, K.; Okada, T.; Sofue, K. Hepatic Artery Embolization Induces the Local Overexpression of Transforming Growth Factor $\beta 1$ in a Rat Hepatoma Model. Liver Cancer 2020, 9, 63-72, http://doi.org/10.1159/000502774.

14. Yang, Z.; Duan, J.; Wang, J.; Liu, Q.; Shang, R.; Yang, X.; Lu, P.; Xia, C.; Wang, L.; Dou, K. Superparamagnetic iron oxide nanoparticles modified with polyethylenimine and galactose for siRNA targeted delivery in hepatocellular carcinoma therapy. Int. J. Nanomedicine 2018, 13, 1851-1865, http://doi.org/10.2147/IJN.S155537.

15. Sayed, R.; Sabry, D.; Mostafa-Hedeab, G.; Ali, H.H.M. In vitro characterization and evaluation of silver nanoparticles cytotoxicity on human "liver and breast" cancer cells versus normal melanocytes. Egypt. J. Histol. 2019, 42, 755-766, http://doi.org/10.21608/ejh.2019.6981.1058.

16. Kariyama, K.; Nouso, K.; Wakuta, A.; Oonishi, A.; Toyoda, H.; Tada, T.; Hiraoka, A.; Tsuji, K.; Itobayashi, E.; Ishikawa, T. Treatment of Intermediate-Stage Hepatocellular Carcinoma in Japan: Position of Curative Therapies. Liver Cancer 2020, 9, 41-49, http://doi.org/10.1159/000502479.

17. Rizvi, S.; Fischbach, S.R.; Bronk, S.F.; Hirsova, P.; Krishnan, A.; Dhanasekaran, R.; Smadbeck, J.B.; Smoot, R.L.; Vasmatzis, G.; Gores, G.J. YAP-associated chromosomal instability and cholangiocarcinoma in mice. Oncotarget 2018, 9, 5892-5905, http://doi.org/10.18632/oncotarget.23638.

18. Phytochemical and Toxicological Effect of Ethanol Extract of Heliotropium Indicum on Liver of Male Albino Rats. Lett. Appl. NanoBioScience 2020, 10, 2085-2095, http://doi.org/10.33263/LIANBS102.20852095.

19. K. Karthick; Kumaran, K.S.G.A. Formulation and Preclinical Evaluation of Niosomes Co-Loaded With 5Fluorouracil and Leucovorin. Int. J. Res. Pharm. Nano Science 2016, 5, 283-292.

20. Sheikh I.; Sankhyan A.; Sharma V.; Diwakar A.; Sharma A. Anti-cancer potential of natural products: recent trends, scope and relevance. Lett. Appl. NanoBioScience 2020, 9, 902-907, http://doi.org/10.33263/LIANBS91.902907.

21. El-Shanshoury R. R.; Ebeid E. Z.; Elsik S.; Mohamed S. F.; El -Zeiny Ebeid M. Biogenic Synthesis of Gold Nanoparticles by Bacteria and Utilization of the Chemical Fabricated for Diagnostic Performance of Viral Hepatitis C Virus-NS4. Letters in Applied NanoBioScience 2020, 9, 1395-1408, http://doi.org/10.33263/LIANBS93.13951408.

22. Sim, J.H.; Kim, S.H.; Jun, I.G.; Kang, S.J.; Kim, B.; Kim, S.; Song, J.G. The association between prognostic nutritional index (Pni) and intraoperative transfusion in patients undergoing hepatectomy for hepatocellular carcinoma: A retrospective cohort study. Cancers (Basel) 2021, 13, http://doi.org/10.3390/cancers13112508.

23. Song, Y.; Wang, S.; Cheng, X. LINC01006 regulates the proliferation, migration and invasion of hepatocellular carcinoma cells through regulating miR-433-3p/CBX3 axis. Ann. Hepatol. 2021, 25, 100343, http://doi.org/10.1016/J.AOHEP.2021.100343.

24. Vogel, A.; Martinelli, E.; Vogel, A.; Cervantes, A.; Chau, I.; Daniele, B.; Llovet, J.M.; Meyer, T.; Nault, J.C.; Neumann, U. Updated treatment recommendations for hepatocellular carcinoma (HCC) from the ESMO Clinical Practice Guidelines. Ann. Oncol. 2021, 32, 801-805, http://doi.org/10.1016/J.ANNONC.2021.02.014.

25. Woitok, M.M.; Zoubek, M.E.; Doleschel, D.; Bartneck, M.; Mohamed, M.R.; Kießling, F.; Lederle, W.; Trautwein, C.; Cubero, F.J. Lipid-encapsulated siRNA for hepatocyte-directed treatment of advanced liver disease. Cell Death Dis. 2020, 11, http://doi.org/10.1038/s41419-020-2571-4.

26. Parizadeh, S.M.; Jafarzadeh-Esfehani, R.; Ghandehari, M.; Goldani, F.; Parizadeh, S.M.R.; Hassanian, S.M.; Ghayour-Mobarhan, M.; Ferns, G.A.; Avan, A. MicroRNAs as Potential Diagnostic and Prognostic Biomarkers in Hepatocellular Carcinoma. Current Drug Targets 2019, 20, 1129-1140, http://doi.org/10.2174/1389450120666190307095720.

27. Heo, M.J.; Yun, J.; Kim, S.G. Role of non-coding RNAs in liver disease progression to hepatocellular carcinoma. Arch. Pharm. Res. 2019, 42, 48-62, http://doi.org/10.1007/s12272-018-01104-X.

28. Wong, R.J.; Aguilar, M.; Cheung, R.; Perumpail, R.B.; Harrison, S.A.; Younossi, Z.M.; Ahmed, A. Nonalcoholic steatohepatitis is the second leading etiology of liver disease among adults awaiting liver transplantation in the United States. Gastroenterology 2015, 148, 547-555, http://doi.org/10.1053/J.GASTRO.2014.11.039.

29. Taha, H.; Elfar, N.; Haffez, H.; Hassan, Z.A. Raptinal silver nanoparticles: new therapeutic advances in hepatocellular carcinoma mouse model. Naunyn. Schmiedebergs. Arch. Pharmacol. 2020, http://doi.org/10.1007/s00210-020-01973-4.

30. Simoni-Nieves, A.; Clavijo-Cornejo, D.; Salas-Silva, S.; Escobedo-Calvario, A.; Bucio, L.; Souza, V.; Gutiérrez-Ruiz, M.C.; Miranda-Labra, R.U.; Gomez-Quiroz, L.E. HGF/c-Met regulates p22phox subunit of 
the NADPH oxidase complex in primary mouse hepatocytes by transcriptional and post-translational mechanisms. Ann. Hepatol. 2021, 25, 100339, http://doi.org/10.1016/J.AOHEP.2021.100339.

31. Zhu, A.X. Predicting the response to sorafenib in hepatocellular carcinoma: Where is the evidence for phosphorylated extracellular signaling-regulated kinase (pERK)? BMC Med. 2009, 7, 42, http://doi.org/10.1186/1741-7015-7-42.

32. Zhang, H.; Shang, Y.P.; Chen, H.Y.; Li, J. Histone deacetylases function as novel potential therapeutic targets for cancer. Hepatol. Res. 2017, 47, 149-159, http://doi.org/10.1111/HEPR.12757.

33. Liu, Y.X.; Li, Q.Z.; Cao, Y.N.; Zhang, L.Q. Identification of key genes and important histone modifications in hepatocellular carcinoma. Comput. Struct. Biotechnol. J. 2020, 18, 2657-2669, http://doi.org/10.1016/j.csbj.2020.09.013.

34. Ren, K.W.; Li, Y.H.; Wu, G.; Ren, J.Z.; Lu, H. Bin; Li, Z.M.; Han, X.W. Quercetin nanoparticles display antitumor activity via proliferation inhibition and apoptosis induction in liver cancer cells. Int. J. Oncol. 2017, 50, 1299-1311, http://doi.org/10.3892/ijo.2017.3886.

35. Amaddeo, G.; Brustia, R.; Allaire, M.; Lequoy, M.; Hollande, C.; Regnault, H.; Blaise, L.; Ganne-Carrié, N.; Séror, O.; Larrey, E. Impact of COVID-19 on the management of hepatocellular carcinoma in a highprevalence area. JHEP Reports 2021, 3, 100199, http://doi.org/10.1016/J.JHEPR.2020.100199.

36. Choi, K.J.; Baik, I.H.; Ye, S.K.; Lee, Y.H. Molecular targeted therapy for hepatocellular carcinoma: Present status and future directions. Biol. Pharm. Bull. 2015, 38, 986-991, http://doi.org/10.1248/BPB.B15-00231.

37. Zeng, X.; Sun, J.; Li, S.; Shi, J.; Gao, H.; Sun Leong, W.; Wu, Y.; Li, M.; Liu, C.; Li, P. Blood-triggered generation of platinum nanoparticle functions as an anticancer agent. Nat. Commun. 2020, 11, http://doi.org/10.1038/s41467-019-14131-z.

38. Johnson, P.J.; Qin, S.; Park, J.W.; Poon, R.T.P.; Raoul, J.L.; Philip, P.A.; Hsu, C.H.; Hu, T.H.; Heo, J.; Xu, J. Brivanib versus sorafenib as first-line therapy in patients with unresectable, advanced hepatocellular carcinoma: Results from the randomized phase III BRISK-FL study. Journal Clin. Oncol. 2013, 31, 35173524, http://doi.org/10.1200/JCO.2012.48.4410.

39. Li, Y.; Miao, Y.; Chen, M.; Chen, X.; Li, F.; Zhang, X.; Gan, Y. Stepwise targeting and responsive lipidcoated nanoparticles for enhanced tumor cell sensitivity and hepatocellular carcinoma therapy. Theranostics 2020, 10, 3722-3736, http://doi.org/10.7150/thno.42008.

40. Hao, N.; Yang, H.; Li, L.; Li, L.; Tang, F. The shape effect of mesoporous silica nanoparticles on intracellular reactive oxygen species in A375 cells. New J. Chem. 2014, 38, 4258-4266, http://doi.org/10.1039/c4nj00736k.

41. Bruix, J.; Tak, W.Y.; Gasbarrini, A.; Santoro, A.; Colombo, M.; Lim, H.Y.; Mazzaferro, V.; Wiest, R.; Reig, M.; Wagner, A. Regorafenib as second-line therapy for intermediate or advanced hepatocellular carcinoma: Multicentre, open-label, phase II safety study. Eur. J. Cancer 2013, 49, 3412-3419, http://doi.org/10.1016/j.ejca.2013.05.028.

42. Koch, I.; Baron, A.; Roberts, S.; Junker, U.; Palacay-Ramona, M.; Masson, E.; Kay, A.; Wiedenmann, B.; Laurent, D.; Cebon, J. Influence of hepatic dysfunction on safety, tolerability, and pharmacokinetics (PK) of PTK787/ZK 222584 in patients (Pts) with unresectable hepatocellular carcinoma (HCC). J. Clin. Oncol. 2005, 23, 4134-4134, http://doi.org/10.1200/JCO.2005.23.16_SUPPL.4134.

43. Abou-Alfa, G.K.; Gansukh, B.; Chou, J.F.; Shia, J.; Capanu, M.; Kalin, M.; Chen, H.X.; Zojwalla, N.J.; Katz, S.; Reidy, D.L. Phase II study of cixutumumab (IMC-A12, NSC742460; C) in hepatocellular carcinoma (HCC). J. Clin. Oncol. 2011, 29, 4043-4043, http://doi.org/10.1200/JCO.2011.29.15_SUPPL.4043.

44. Wei, Z.; Doria, C.; Liu, Y. Targeted therapies in the treatment of advanced hepatocellular carcinoma. Clin. Med. Insights Oncol. 2013, 7, 87-102, http://doi.org/10.4137/CMO.S7633.

45. Faivre, S.J.; Fartoux, L.; Bouattour, M.; Bumsel, F.; Dreyer, C.; Raymond, E.; Rosmorduc, O. A phase I study of AVE1642, a human monoclonal antibody-blocking insulin-like growth factor-1 receptor (IGF-1R), given as a single agent and in combination with sorafenib as first-line therapy in patients with advanced hepatocellular carcinoma (HCC). Journal Clinical Oncology 2011, 29, 270-270, http://doi.org/10.1200/JCO.2011.29.4_SUPPL.270.

46. Paraskevis, D.; Magiorkinis, G.; Magiorkinis, E.; Ho, S.Y.W.; Belshaw, R.; Allain, J.P.; Hatzakis, A. Dating the origin and dispersal of hepatitis B virus infection in humans and primates. Hepatology 2013, 57, 908916, http://doi.org/10.1002/hep.26079.

47. Ngamcherdtrakul, W.; Morry, J.; Gu, S.; Castro, D.J.; Goodyear, S.M.; Sangvanich, T.; Reda, M.M.; Lee, R.; Mihelic, S.A.; Beckman, B.L. Cationic polymer modified mesoporous silica nanoparticles for targeted siRNA 
delivery to HER2+ breast cancer. Adv. Funct. Mater. 2015, 25, 2646-2659, http://doi.org/10.1002/adfm.201404629.

48. Ishida, Y.; Nagata, K. Hsp47 as a collagen-specific molecular chaperone. Methods Enzymol. 2011, 499, 167182, http://doi.org/10.1016/B978-0-12-386471-0.00009-2.

49. Jia, L.; Gao, Y.; He, Y.; Hooper, J.D.; Yang, P. HBV induced hepatocellular carcinoma and related potential immunotherapy. Pharmacol. Res. 2020, 159, http://doi.org/10.1016/J.PHRS.2020.104992.

50. Kunjiappan, S.; Sankaranarayanan, M.; Karankumar, B.; Parasuraman, P.; Babkiewicz, E.; Maszczyk, P.; Glodkowska-Mrowka, E.; Arunachalam, S.; Ram Kumar Pandian, S.; Ravishankar, V. Capsaicin-loaded solid lipid nanoparticles: Design, biodistribution, in silico modeling and in vitro cytotoxicity evaluation. Nanotechnology 2020, http://doi.org/10.1088/1361-6528/abc57e.

51. Choudhari, S.R.; Khan, M.A.; Harris, G.; Picker, D.; Jacob, G.S.; Block, T.; Shailubhai, K. Deactivation of Akt and STAT3 signaling promotes apoptosis, inhibits proliferation, and enhances the sensitivity of hepatocellular carcinoma cells to an anticancer agent, Atiprimod. Molecular Cancer Therapeutics 2007, 6, 112-121, http://doi.org/10.1158/1535-7163.MCT-06-0561.

52. Hajarizadeh, B.; Grebely, J.; Dore, G.J. Epidemiology and natural history of HCV infection. Nat. Rev. Gastroenterol. Hepatol. 2013, 10, 553-562, http://doi.org/10.1038/nrgastro.2013.107.

53. Anton, N.; Parlog, A.; Bou About, G.; Attia, M.F.; Wattenhofer-Donzé, M.; Jacobs, H.; Goncalves, I.; Robinet, E.; Sorg, T.; Vandamme, T.F. Non-invasive quantitative imaging of hepatocellular carcinoma growth in mice by micro-CT using liver-targeted iodinated nano-emulsions. Sci. Rep. 2017, 7, 1-13, http://doi.org/10.1038/s41598-017-14270-7.

54. Li, W.J.; Lian, Y.W.; Guan, Q.S.; Li, N.; Liang, W.J.; Liu, W.X.; Huang, Y. Bin; Cheng, Y.; Luo, H. Livertargeted delivery of liposome-encapsulated curcumol using galactosylated-stearate. Exp. Ther. Med. 2018, 16, 925-930, http://doi.org/10.3892/etm.2018.6210.

55. Goossens, N.; Hoshida, Y. Hepatitis C virus-induced hepatocellular carcinoma. Clin. Mol. Hepatol. 2015, 21 , 105-114, http://doi.org/10.3350/CMH.2015.21.2.105.

56. Irshad, M.; Gupta, P.; Irshad, K. Molecular basis of hepatocellular carcinoma induced by hepatitis $\mathrm{C}$ virus infection. World J. Hepatol. 2017, 9, 1305-1314, http://doi.org/10.4254/wjh.v9.i36.1305.

57. Vescovo, T.; Refolo, G.; Vitagliano, G.; Fimia, G.M.; Piacentini, M. Molecular mechanisms of hepatitis C virus-induced hepatocellular carcinoma. Clin. Microbiol. Infect. 2016, 22, 853-861, http://doi.org/10.1016/j.cmi.2016.07.019.

58. Desai, A.; Sandhu, S.; Lai, J.P.; Sandhu, D.S. Hepatocellular carcinoma in non-cirrhotic liver: A comprehensive review. World J. Hepatol. 2019, 11, 1-18, http://doi.org/10.4254/WJH.V11.I1.1.

59. Ogawa, E.; Nomura, H.; Nakamuta, M.; Furusyo, N.; Kajiwara, E.; Dohmen, K.; Kawano, A.; Ooho, A.; Azuma, K.; Takahashi, K. Incidence of hepatocellular carcinoma after treatment with sofosbuvir-based or sofosbuvir-free regimens in patients with chronic hepatitis C. Cancers (Basel) 2020, 12, 1-13, http://doi.org/10.3390/cancers12092602.

60. Galicia-Moreno, M.; Silva-Gomez, J.A.; Lucano-Landeros, S.; Santos, A.; Monroy-Ramirez, H.C.; Armendariz-Borunda, J. Liver Cancer: Therapeutic Challenges and the Importance of Experimental Models. Can. J. Gastroenterol. Hepatol. 2021, http://doi.org/10.1155/2021/8837811.

61. Medhat, A.; Mansour, S.; El-Sonbaty, S.; Kandil, E.; Mahmoud, M. Evaluation of the antitumor activity of platinum nanoparticles in the treatment of hepatocellular carcinoma induced in rats. Tumor Biol. 2017, 39, http://doi.org/10.1177/1010428317717259. 